\title{
Caculation of sterilization conditions using Ball method and shelf life for canned salmon fish bone extract
}

\author{
Tuyen C. Kha*, \& Anh T. Vu
}

Faculty of Food Science and Technology, Nong Lam University, Ho Chi Minh City, Vietnam

\begin{tabular}{|c|c|}
\hline ARTICLE INFO & ABSTRACT \\
\hline $\begin{array}{l}\text { Received: May 08, } 2018 \\
\text { Revised: July 18, } 2018 \\
\text { Accepted: July } 31,2018 \\
\text { Keywords } \\
\text { Ball method } \\
\text { Canned food } \\
\text { Fish bone extract } \\
\text { Salmon fish bone } \\
\text { Sterilization }\end{array}$ & $\begin{array}{l}\text { The objective of this study aimed to determine sterilization condi- } \\
\text { tions (temperature and time) in order to maximize sensory quality } \\
\text { and color of the canned salmon bone extract and minimize harm- } \\
\text { ful organisms at the lowest level. The study was also designed to } \\
\text { predict the shelf life of the canned extract. The sterilization condi- } \\
\text { tions were calculated using the Ball method. The results showed } \\
\text { that two sterilization conditions to achieve the } \mathrm{F}_{0} \text { value of } 2.8 \\
\text { min were determined at } 121^{\circ} \mathrm{C} \text { for } 14 \text { min and } 116^{\circ} \mathrm{C} \text { for } 27 \text { min. } \\
\text { According to quality assessment, there were no significant differ- } \\
\text { ences in color and pH of the product sterilized at such conditions. } \\
\text { However, overall score of the product sterilized at } 121^{\circ} \mathrm{C} \text { for } 14 \\
\text { min was found to be better than that of the lower temperature } \\
\text { and longer time in terms of sensory evaluation. For the shelf life } \\
\text { prediction, the acceleration testing method was used with differ- } \\
\text { ent responses measured including color, pH and sensory quality. } \\
\text { The product was stored at } 30^{\circ} \mathrm{C} \text { for } 60 \text { days, and at } 45 \text { and } 55^{\circ} \mathrm{C} \\
\text { for } 20 \text { days. Several kinetic equations have been constructed to } \\
\text { describe the changes of those responses during storage periods. } \\
\text { According to kinetics equations, the shelf life of the product was } \\
\text { predicted and confirmed as } 19 \text { months at } 30^{\circ} \mathrm{C} \text {. }\end{array}$ \\
\hline
\end{tabular}

Cited as: Kha, T. C., \& Vu, A. T. (2019). Caculation of sterilization conditions using Ball method and shelf life for canned salmon fish bone extract. The Journal of Agriculture and Development 18(1), 117-126. 


\title{
Xác định chế độ tiệt trùng bằng phương pháp Ball và thời gian bảo quản sản phẩm nước cốt xương cá hồi đóng lon
}

\author{
Kha Chấn Tuyền* \& Vũ Thùy Anh
}

Khoa Công Nghệ Thực Phẩm, Trường Đại Học Nông Lâm TP. Hồ Chí Minh, TP. Hồ Chí Minh

\section{THÔNG TIN BÀI BÁO}

Bài báo khoa học

Ngày nhận: 08/05/2018

Ngày chỉnh sửa: 18/07/2018

Ngày chấp nhận: 31/07/2018

\section{Từ khóa}

Đồ hộp

Nước cốt xương cá

Phương pháp Ball

Tiệt trùng

Xương cá hồi

*Tác giả liên hệ

Kha Chấn Tuyền

Email: khachantuyen@hcmuaf.edu.vn

\section{TÓM TẮT}

Mục tiêu của đề tài là xác định chế độ tiệt trùng thích hợp sao cho giá trị cảm quan và màu sắc của sản phẩm nước cốt xương cá hồi đóng lon là tốt nhất và đồng thời đảm bảo tiêu diệt được các vi sinh vật có hại gây ảnh hưởng đến sức khoẻ người tiêu dùng. Nghiên cứu cũng được thiết kế nhằm xác định thời gian bảo quản cho sản phẩm. Chế độ tiệt trùng được thiết kế và tính toán bằng phương pháp Ball. Kết quả nghiên cứu đã xác định được 2 chế độ tiệt trùng đảm bảo giá trị tiệt trùng $\mathrm{F}_{0}$ (2,8 phút) cho sản phẩm là $121^{\circ} \mathrm{C}$ trong 14 phút và $116^{\circ} \mathrm{C}$ trong 27 phút. Kết quả đánh giá ảnh hưởng của chế độ tiệt trùng đến chất lượng của sản phẩm cho thấy không có khác biệt về màu sắc và $\mathrm{pH}$, tuy nhiên kết quả chất lượng cảm quan tốt hơn ở $121^{\circ} \mathrm{C}$ trong 14 phút. Việc xác định thời gian bảo quản sản phẩm bằng phương pháp gia tốc với các chỉ tiêu khảo sát là màu sắc, $\mathrm{pH}$ và đánh giá cảm quan. Sản phẩm nước cốt xương cá hồi được bảo quản ở nhiệt độ $30^{\circ} \mathrm{C}$ trong 60 ngày và ở nhiệt độ $45^{\circ} \mathrm{C}$ và $52^{\circ} \mathrm{C}$ trong 20 ngày. Dựa vào các giới hạn cho phép của từng chỉ tiêu, bằng phương trình hồi quy và hệ thức Arrhenius để tính toán các thông số động học của nhiệt độ tham chiếu $30^{\circ} \mathrm{C}$. Xác định được thời gian bảo quản sản phẩm là 19 tháng.

\section{1. Đặt Vấn Đề}

Theo hiệp hội chế biến và xuất khẩu thuỷ sản Việt Nam, trong năm 2014 giá trị xuất khẩu cá hồi đạt khoảng 6 tỷ USD, tăng 2,4\% so với năm 2013. Khi sản lượng xuất khẩu tăng cao thì lượng phụ phẩm dư thừa (chiếm hơn $50 \%$ trọng lượng cá hồi) cũng cao. Hiện nay lượng cá hồi nuôi khoảng 700 - 1000 tấn cá/năm. Về cá hồi nhập khẩu, trong những năm qua các công ty Việt Nam nhập khẩu hơn 230 ngàn tấn cá hồi/năm và như vậy lượng phụ phẩm được thải ra mỗi năm là rất lớn, khoảng 117 ngàn tấn. Các hợp chất sinh học có lợi cho sức khoẻ con người có trong các nguồn phụ phẩm này là rất cao, cụ thể là protein, canxi, và axít béo không no, đặc biệt là axít béo omega-3.

Kết quả khảo sát sơ bộ cho thấy một công ty sản xuất phi lê cá hồi ở Thành phố Hồ Chí Minh có lượng phụ phẩm (bao gồm xương, da, bụng, đầu cá,...) dư ra hàng tháng là khoảng 25 - 30 tấn. Với lượng phụ phẩm xương cá hồi dồi dào có thể chế biến thành sản phẩm xương hầm có giá trị dinh dưỡng cao như giàu đạm và canxi. Sản phẩm xương hầm có thể cạnh tranh với các sản phẩm tương tự có trên trường Việt Nam như nước cốt gà Brand's với giá thành rất cao (40 ngàn đồng/hũ $70 \mathrm{~mL}$ ). Vì thế việc tận dụng xương cá hồi để chế biến thành sản phẩm nước cốt xương cá hồi không những giúp cho người dân (đặc biệt là người có thu nhập thấp) có thể sử dụng sản phẩm có giá trị dinh dưỡng cao mà còn giúp cho các công ty chế biến tăng lợi nhuận. Ngoài giá trị dinh dưỡng của sản phẩm, giá trị cảm quan cũng không kém phần quan trọng trong việc đưa sản phẩm đến tay người tiêu dùng, vì vậy cần tiến hành phối chế sản phẩm sao cho dễ uống hơn.

Xương cá hồi sau khi trải qua công đoạn rửa, hầm, lọc, cô đặc, rót nóng,... thì số vi sinh vật có trong nguyên liệu thực phẩm đã giảm xuống nhiều nhưng có thể vẫn còn sống sót hoặc xâm 
nhập từ môi trường bên ngoài vào thực phẩm trong quá trình chế biến, vì vậy có thể chưa đảm bảo an toàn về mặt vi sinh. Để góp phần bảo quản đồ hộp trong thời gian dài mà không bị hư hỏng cần phải tiêu diệt các vi sinh vật sống sót ây. Hơn nữa, nước cốt xương cá hồi có $\mathrm{pH}$ là $5,6 \pm$ 0,1 , tức là thuộc nhóm có độ axít thấp $(\mathrm{pH}>4,5)$ nên cần chế độ xử lý nhiệt lớn hơn $100^{\circ} \mathrm{C}$, cũng nhằm tiêu diệt cả bào tử của vi sinh vật, được gọi là tiệt trùng (Fellows, 2009). Phương pháp Ball là một trong những phương pháp tính toán chế độ tiệt trùng thực tế, thông qua việc sử dụng các thông số của quá trình thâm nhập nhiệt nhằm xác định thời gian cần thiết để đạt được giá trị tiệt trùng nhất định $\mathrm{F}_{0}$ ở mức nhiệt độ nào đó.

Sau khi tiệt trùng, sản phẩm muốn đưa ra thị trường cần biết được thời gian bảo quản. Đối với thực phẩm, thời gian bảo quản là thời gian trước khi sản phẩm trở nên không thể chấp nhận về cảm quan, dinh dưỡng hoặc xa hơn là sự an toàn $(\mathrm{Fu}$ \& Labuza, 1993). Để xác định chính xác thời gian bảo quản, cần phải theo dõi định kỳ, liên tục sản phẩm từ lúc bắt đầu sản xuất đến lúc một trong các tiêu chuẩn yêu cầu của sản phẩm không còn đạt chuẩn nữa với điều kiện lưu trữ giống như trên thị trường. Tuy nhiên, nước cốt xương cá hồi đóng lon tiệt trùng và các sản phẩm tương tự khác thường có thời gian bảo quản tương đối dài trong khi cần phải đưa vào thị trường càng sớm càng tốt. Ứng dụng phương pháp động học để tính toán nhanh thời gian bảo quản sản phẩm với nguyên nhân hết hạn là do sản phẩm bị thoái hóa bởi nhiệt độ theo thời gian đang ngày càng được quan tâm. Phương pháp tính toán nhanh hạn sử dụng tiện lợi và kinh tế nhưng việc theo dõi thêm sản phẩm ở điều kiện lưu trữ bình thường là cần thiết.

Từ những vấn đề trên, đề tài được thực hiện nhằm xác định chế độ tiệt trùng thích hợp nhằm đảm bảo chất lượng vi sinh, màu sắc và cảm quan. Đồng thời, thời gian bảo quản sản phẩm ở điều kiện nhiệt độ môi trường cũng cần được xác định.

\section{Vật Liêuu và Phương Pháp Nghiên Cứu}

\subsection{Vật liệu}

Xương cá hồi, phụ phẩm từ quá trình phi lê cá hồi được lấy từ công ty Sai Gon Food, TP. Hồ Chí Minh. Xương cá hồi sau khi phi lê sẽ được bảo quản lạnh ngay bằng đá vảy sau đó vận chuyển về xưởng Chế biến thịt cá Khoa Công nghệ Thực phẩm, Trường Đại học Nông Lâm Thành phố Hồ Chí Minh để rửa sạch và cấp đông hoặc tiến hành làm sản phẩm ngay. Xương cá hồi có màu sắc bình thường, không có mùi lạ, không lẫn tạp chất.

Đường cỏ ngọt Hermesetas Stevia sản xuất tại Hermes Sweeteners Ltd., Thụy Sỹ. Các nguyên liệu và phụ gia thực phẩm khác được mua tại siêu thị CoopXtra Thủ Đức.

\subsection{Phương pháp nghiên cứu}

Xương cá hồi sau khi được thu mua về sẽ tiến hành loại bỏ đuôi, màng bụng, máu trong các khe xương sống rồi rửa sạch bằng nước. Ngâm xương cá hồi trong nước giấm loãng và dùng gừng nghiền nát chà xát lên cá, để trong 2 phút nhằm khử bớt mùi tanh của cá sau đó vớt ra và rửa lại với nước. Cân xương cá hồi và nước với tỷ lệ 1:1, mỗi mẻ $4 \mathrm{~kg}$ xương. Tiến hành xử lý nhiệt ở $115^{0} \mathrm{C}$ trong 75 phút, sau đó để nguội và dùng túi vải lọc tách riêng phần bã, thu được dịch thô. Tiến hành rót dịch thô vào bình chiết quả lê $(500$ $\mathrm{mL}$ ), sau đó hạ nhiệt độ của dịch thô xuống $5^{0} \mathrm{C}$ trong 50 phút trong ngăn mát tủ lạnh, lúc này có hiện tượng tách lớp, mỡ nổi lên trên, dịch trong ở phía dưới. Mở van xả của bình chiết quả lê thu được lượng dịch trong có độ Brix là $3,5 \pm 0,2$. Loại bỏ phần mỡ phía trên. Tiến hành cô đặc sản phẩm bằng phương pháp cách đun thủy $100^{\circ} \mathrm{C}$ đến khi đạt độ Brix $=11$. Khi nhiệt độ dịch nước cốt xương cá hồi đạt $100^{\circ} \mathrm{C}$, phối trộn sản phẩm với 1,5\% $\beta$-Cyclodextrin $(\beta$-CD), đường cỏ ngọt và gừng. Tiếp theo, lọc để loại bỏ phần gừng ra khỏi hỗn hợp và một phần chất béo còn sót lại. Trước khi rót lon, bài khí và ghép nắp (máy ghép nắp Scim, Pháp), lon phải được hấp tiệt trùng. Tiến hành cân và rót nóng dịch nước cốt xương cá hồi (nhiệt độ rót là $80-90^{\circ} \mathrm{C}$ ) vào lon có kích cỡ 307 ( $\Phi$ 84). Sau khi tiệt trùng trong thiết bị tiệt trùng (Wisd Laboratory instruments, Đức) có gắn đầu dò đo nhiệt độ tâm sản phẩm, phải làm nguội lon nước cốt xương cá hồi nhanh chóng bằng cách ngâm trong nước lạnh để tránh màu sắc và mùi vị của sản phẩm bị biến đổi. Sau khi tiệt trùng và làm nguội, những lon nước cốt xương cá hồi được lau khô và bảo ôn. Trong thời gian bảo ôn, nước cốt xương cá hồi được tiếp tục ổn định về mặt phẩm chất và có thể phát hiện được các lon hỏng, hiện tượng phồng hộp do vi khuẩn sinh khí. Tiến hành bảo ôn trong 21 ngày ở nhiệt độ môi trường trước khi kiểm tra vi sinh. 


\subsubsection{Tính toán giá trị tiệt trùng sản phẩm nước} cốt xương cá hồi

Tính toán chế độ tiệt trùng sản phẩm nước cốt xương cá hồi theo phương pháp công thức Ball (Stoforos, 2010). Tính toán thời gian tiệt trùng cần thiết trên 2 mức nhiệt độ tiệt trùng phổ biến là 121 và $116^{\circ} \mathrm{C}$ để đạt giá trị tiệt trùng $\mathrm{F}_{0}$. Nhiệt dộ ban đầu $\mathrm{T}_{0}\left({ }^{0} \mathrm{C}\right)$, thời gian nâng nhiệt tc (phút), nhiệt độ nồi tiệt trùng $\mathrm{T}_{\mathrm{R}}\left({ }^{0} \mathrm{C}\right)$, khác biệt giữa nhiệt độ tâm sản phẩm so với nhiệt độ nồi tiệt trùng $\left(\mathrm{T}_{\mathrm{R}}-\mathrm{T}\right)$ được ghi nhận và tính toán ở các khoảng thời gian khác nhau. Cắm đầu đò nhiệt độ tâm vào lon sản phẩm sao cho cảm biến nhiệt nằm cách đáy $1 / 3$ chiều cao lon (truyền nhiệt đối lưu) rồi tiến hành tiệt trùng. Theo dõi diễn tiến nhiệt độ nồi tiệt trùng và tâm sản phẩm sau mỗi 2 phút. Thẩm tra chế độ tiệt trùng vừa

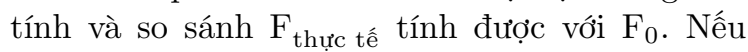
$\mathrm{F}_{\text {thực tế }} \geq \mathrm{F}_{0}$ thì chế độ tiệt trùng đạt.

Sử dụng các thông số của quá trình thâm nhập nhiệt. Thiết kế quá trình xử lý nhiệt là việc xác định thời gian cần thiết để đạt được giá trị tiệt trùng nhất định $\mathrm{F}_{0}$. Đánh giá quá trình xử lý nhiệt là việc xác định sự đạt được giá trị tiệt trùng (hiệu quả tiệt trùng) qua quá trình xử lý. Ball đưa ra công thức tính giá trị tiệt trùng cho các tình huống mới bằng cách sử dụng các giá trị $\mathrm{f}$ và $\mathrm{j}$ được lấy từ thí nghiệm thực tế của các sản phẩm khác nhau. Trong suốt thời gian nâng nhiệt $t_{c}$, tốc độ tiêu diệt vi sinh vật luôn luôn thay đổi. Ball đề nghị thay thế điều này với một đường cong duy trì tại thời gian bắt đầu của thời gian nâng nhiệt là $58 \%$. Nếu sử dụng thời gian xử lý Ball, phương trình đường cong xử lý nhiệt trở thành:

$$
\log \left(\mathrm{T}_{\mathrm{R}}-\mathrm{T}_{\mathrm{B}}\right)=\log \left[\mathrm{j}_{\mathrm{h}} \times\left(\mathrm{T}_{\mathrm{R}}-\mathrm{T}_{0}\right)\right]-\mathrm{t}_{\mathrm{B}} / \mathrm{f}_{\mathrm{h}}
$$

Đặt $\mathrm{g}=\mathrm{T}_{\mathrm{R}}-\mathrm{T}_{\mathrm{B}}$ là sự khác nhau giữa nhiệt độ tối đa của sản phẩm và nhiệt độ môi trường xử lý nhiệt thì ta có phương trình (2):

$$
\log (\mathrm{g})=\log \left[\mathrm{j}_{\mathrm{h}} \times\left(\mathrm{T}_{\mathrm{R}}-\mathrm{T}_{0}\right)\right]-\mathrm{t}_{\mathrm{B}} / \mathrm{f}_{\mathrm{h}}
$$

Vậy thời gian xử lý nhiệt Ball cần thiết:

$$
\mathrm{t}_{\mathrm{B}}=\mathrm{f}_{\mathrm{h}} \times\left\{\log \left[\mathrm{j}_{\mathrm{h}} \times\left(\mathrm{T}_{\mathrm{R}}-\mathrm{T}_{0}\right)\right]-\log (\mathrm{g})\right\}
$$

2.2.2. Ảnh hưởng của chế độ tiệt trùng đến $\mathrm{pH}$, màu sắc và cảm quan sản phẩm

So sánh 2 chế độ tiệt trùng là $116^{0} \mathrm{C}$ trong 27 phút và $121^{\circ} \mathrm{C}$ trong 14 phút dựa vào các chỉ tiêu nhằm xác định chế độ tiệt trùng phù hợp nhất với sản phẩm nước cốt xương cá hồi. Thí nghiệm được bố trí hoàn toàn ngẫu nhiên 1 yếu tố với 3 lần lặp lại. Yếu tố thí nghiệm là chế độ tiệt trùng. Thí nghiệm gồm 2 nghiệm thức: $116^{\circ} \mathrm{C}$ trong 27 phút và $121^{\circ} \mathrm{C}$ trong 14 phút. Chỉ tiêu theo dõi là $\mathrm{pH}$, màu sắc $\left(\mathrm{L}^{*}, \mathrm{a}^{*}, \mathrm{~b}^{*}\right)$, điểm cảm quan của sản phẩm ở 2 chế độ tiệt trùng.

\subsubsection{Xác định thời gian bảo quản sản phẩm nước cốt xương cá hồi}

Thí nghiệm được bố trí hoàn toàn ngẫu nhiên 1 yếu tố với 3 lần lặp lại. Yếu tố thí nghiệm là nhiệt độ bảo quản: nhiệt độ 30 (nhiệt độ môi trường), 45 và $52^{0} \mathrm{C}$. Các chỉ tiêu màu sắc và cảm quan được đánh giá trong quá trình bảo quản. Dựa vào các giới hạn cho phép của từng chỉ tiêu, phương trình hồi quy và hệ thức Arrhenius được sử dụng để tính toán các thông số động học thất thoát màu sắc và giá trị cảm quan, từ đó ước tính thời gian quản quản sản phẩm.

Sự suy giảm màu sắc và điểm cảm quan của nước cốt xương cá hồi được tính toán bằng cách sử dụng phương trình tiêu chuẩn cho một mô hình động học bậc một như sau: $\ln \mathrm{A}=\ln \mathrm{A}_{0}-\mathrm{kt}$.

Trong đó, $\mathrm{A}$ là giá trị màu sắc và điểm cảm quan tại thời gian $\mathrm{t} ; \mathrm{A}_{0}$ là giá trị màu sắc và điểm cảm quan ban đầu (trước khi quản quản); $\mathrm{k}$ là hằng số tốc độ suy thoái ( $1 /$ ngày) thu được từ độ dốc của một đồ thị $\ln \left(\mathrm{A} / \mathrm{A}_{0}\right)$ theo thời gian; $\mathrm{t}$ là thời gian bảo quản (ngày). Thời gian bảo quản thì được tính toán tại một nhiệt độ bằng công thức: $\mathrm{t}_{1 / 2}=(\ln 2) / \mathrm{k}$. Năng lượng hoạt hóa $\left(\mathrm{E}_{\mathrm{a}}, \mathrm{kcal} / \mathrm{mol}\right)$ được xác định bằng phương trình Arrhenius sau:

$$
\mathrm{k}=\mathrm{k}_{\mathrm{A}} \times e^{-\frac{\mathrm{E}_{\mathrm{a}}}{\mathrm{RT}}}
$$

\section{Trong đó:}

$\mathrm{k}_{\mathrm{A}}$ là hằng số đại diện cho phương trình Arrhenius, phụ thuộc nhiệt độ.

$\mathrm{R}$ là hằng số khí lý tưởng $(1,9872 \mathrm{kcal} / \mathrm{mol})$.

T là nhiệt độ tuyệt đối $(\mathrm{K})$.

\subsection{Các phương pháp phân tích}

\subsubsection{Xác định chỉ số màu sắc}

Màu sắc của nước cốt xương cá hồi được xác định bằng máy đo màu Minolta Chroma Meter CR-400 (Nhật Bản) được hiệu chuẩn màu trắng là màu tiêu chuẩn. Các kết quả được thể hiện các 
giá trị màu của $L^{*}, a^{*}, b^{*}$, và $L^{*}$ được dùng để chỉ độ sáng, $a^{*}$ chỉ độ đỏ và xanh lục, và b* chỉ độ vàng và xanh lam. Sự khác biệt màu sắc hay sự thay đổi màu $(\Delta \mathrm{E})$ giữa hai mẫu được tính theo công thức sau:

$$
\Delta \mathrm{E}=\sqrt{\left(\mathrm{L}^{*}-\mathrm{L}_{0}^{*}\right)^{2}+\left(\mathrm{a}^{*}-\mathrm{a}_{0}^{*}\right)^{2}+\left(\mathrm{b}^{*}-\mathrm{b}_{0}^{*}\right)^{2}} .
$$

Trong đó $\mathrm{L}_{0}^{*}, \mathrm{a}_{0}^{*}$ và $\mathrm{b}_{0}^{*}$ là những giá trị màu sắc (tương ứng $\mathrm{L}$ : độ sáng, a: từ màu xanh lá đến đỏ và $\mathrm{b}$ : từ màu xanh dương đến vàng) của mẫu tại thời gian ban đầu $t_{0}$ và $L^{*}, a^{*}, b^{*}$ là giá trị được đo của mỗi mẫu ở thời gian $\mathrm{t}$.

Trước khi đo, một lượng cố định mẫu nước cốt xương cá hồi được đóng gói vào túi polyethylene và tiến hành hiệu chuẩn máy với mẫu trắng. Đặt đầu đo vuông góc với mẫu và ghi nhận các giá trị đo được. Giá trị màu sắc của các mẫu được đo ba lần.

\subsubsection{Xác định pH}

Giá trị pH của sản phẩm được đo ở nhiệt độ phòng bằng máy đo $\mathrm{pH}$ để bàn (WTW InoLab). Tại mỗi nhiệt độ bảo quản, lấy 3 lon sản phẩm trộn đều và lấy mẫu đại diện $(50 \mathrm{~g})$ dể đo $\mathrm{pH}$.

\subsection{3. Đánh giá cảm quan}

Đánh giá cảm quan chất lượng của sản phẩm bằng phương pháp cho điểm theo TCVN 3215 79 , tất cả các chỉ tiêu cảm quan hay từng chỉ tiêu riêng biệt của sản phẩm được dùng hệ điểm 20 xây dựng trên một thang thống nhất 6 bậc 5 điểm trong đó có điểm 0 ứng với mức chất lượng sản phẩm bị hỏng, còn từ điểm $1-5$ ứng với mức khuyết tật giảm dần. Tổng hệ số trọng lượng của các chỉ tiêu được đánh giá cho một sản phẩm bằng $4(\mathrm{Ha}, 2000)$.

Người thử (đã được lựa chọn và huấn luyện) sử dụng một thang điểm để đánh giá chất lượng thực phẩm tổng quát và qua đó phân loại chất lượng sản phẩm. Đánh giá theo nhóm chỉ tiêu và từng nhóm chỉ tiêu có một hệ số quan trọng đã được xác định từ trước. Các chuyên gia đánh giá các chỉ tiêu trên một thang điểm có cấu trúc từ 0 "sản phẩm bị hỏng" đến 5 "sản phẩm tốt". Điểm của chỉ tiêu là 5 nếu như trong chỉ tiêu đang xét sản phẩm có tính tốt đặc trưng và rõ rệt cho chỉ tiêu đó, sản phẩm không có khuyết tật và sai lỗi nào và điểm 0 nếu sản phẩm có khuyết tật và sai lỗi ở mức độ trầm trọng, sản phẩm được coi là hỏng và không thể sử dụng được.

\subsubsection{Xác định số lượng vi sinh vật}

Xác định số lượng vi sinh vật được tiến hành kiểm tra tại Công ty TNHH Eurofins Sắc ký Hải Đăng, Thành phố Hồ Chí Minh.

\subsubsection{Xử lý số liệu}

Các số liệu thu thập được xử lý thống kê bằng phần mềm JMP 10.0 và vẽ đồ thị bằng Excel 2010 .

\section{Kết Quả và Thảo Luận}

\subsection{Tính toán chế độ tiệt trùng sản phẩm nước cốt xương cá hồi}

Tính toán chế độ tiệt trùng nhằm xác định thời gian xử lý nhiệt Ball từ đó suy ra thời gian giữ nhiệt của nồi tại nhiệt độ nhất định (chọn 2 mốc nhiệt độ là $121^{\circ} \mathrm{C}$ và $116^{\circ} \mathrm{C}$ ) để đạt giá trị tiệt trùng $\mathrm{F}_{0}$. Trước khi tiệt trùng, mẫu sản phẩm được gửi đi kiểm tra vi sinh vật, kết quả thể hiện trong Bảng 1.

Kết quả cho thấy số lượng vi sinh vật chịu nhiệt $<10 \mathrm{CFU} / \mathrm{g}$, đã đạt về mặt vi sinh. Vậy nên chế độ tiệt trùng được tính theo giá trị Fo lý thuyết, với $\mathrm{N}$ và $\mathrm{No}$ được khuyến cáo lần lượt là $10^{5}$ và $10^{-9}$ (Pflug \& ctv., 1990). Cho nên, giá trị $\mathrm{F}_{0}=$ $\log \left(\mathrm{N}_{0} / \mathrm{N}\right) \times \mathrm{D}=14 \times 0,2=2,8$ (phút). Giá trị $\mathrm{F}_{0}=2,8$ phút là giá trị lý thuyết cần phải đạt được của quá trình tiệt trùng sản phẩm nước cốt xương cá hồi.

Tiến hành tính toán dựa trên các thông số lý thuyết $\mathrm{T}_{\mathrm{ref}}=121,1^{0} \mathrm{C}, \mathrm{z}=10^{\circ} \mathrm{C}, \mathrm{D}=0,2$ phút, $\mathrm{F}_{0}=2,8$ phút. Thí nghiệm tính toán chế độ tiệt trùng lặp lại 3 lần ở mỗi nhiệt độ và thẩm tra chế độ tiệt trùng lặp lại 2 lần. Kết quả tính toán và thẩm tra chế độ tiệt trùng sản phẩm nước cốt xương cá hồi được trình bày thông qua đồ thị semilog và bảng kết quả tính toán thời gian tiệt trùng cho giá trị tiệt trùng $\mathrm{F}_{0}$.

\subsubsection{Chế độ tiệt trùng tại nhiệt độ $121^{0} \mathrm{C}$}

Đường cong truyền nhiệt tại nhiệt độ nồi $121^{\circ} \mathrm{C}$ thể hiện trong Hình 1.

Từ đồ thị semilog Hình 1 thông qua phương trình đường thẳng $\mathrm{y}=77,517 \mathrm{e}^{-0,059 \mathrm{x}}$ tính được giá trị $\mathrm{f}_{\mathrm{h}}=39,02$ phút và sự chênh lệch giữa đường cong truyền nhiệt và đường thẳng biểu kiến tính được $\mathrm{j}_{\mathrm{h}}=1,34$. Tức là sau 39,02 phút thì đường thẳng đi qua 1 chu kì log, sự khác nhau 
Bảng 1. Kết quả vi sinh vật của sản phẩm trước khi tiệt trùng

\begin{tabular}{lcc}
\hline Chỉ tiêu & Đơn vị tính & Kết quả \\
\hline Bào tử chịu nhiệt & CFU $/ \mathrm{g}$ & $<10$ \\
Clostridium perfringens & $\mathrm{CFU} / \mathrm{g}$ & $<10$ \\
Vi khuẩn kỵ khí khử sulfite & $\mathrm{CFU} / \mathrm{g}$ & $<10$ \\
Clostridium botulinum & $/ \mathrm{g}$ & Không phát hiện \\
\hline
\end{tabular}

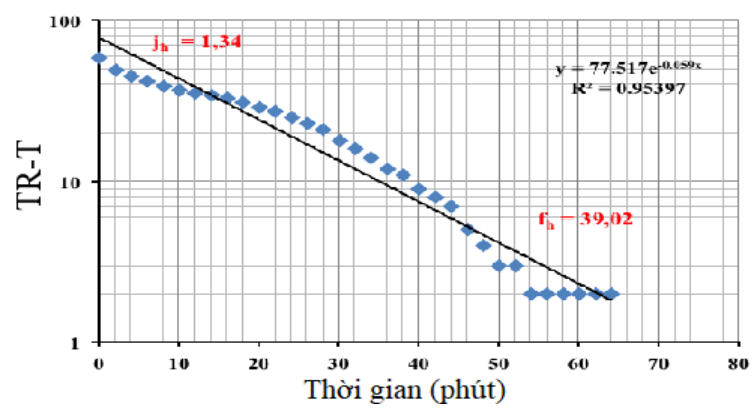

Hình 1. Đường cong truyền nhiệt của sản phẩm tại nhiệt độ nồi $121^{0} \mathrm{C}$.

giữa phần bị chắn thực tế và phần bị chắn biểu kiến là 1,34 (yếu tố trễ pha). Kết quả tính toán cho thấy thời gian xử lý nhiệt Ball là 33,73 phút tại $121^{\circ} \mathrm{C}$. Nhưng trong thực tế có thể thiết bị hoạt động không ổn định, nhiệt bị thất thoát nên cần bù khoảng hao hụt đó, tức là thời gian xử lý nhiệt Ball thực tế cần 35,41 phút (bù thêm 5\%).

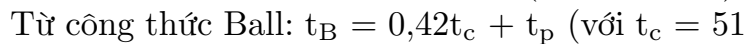
phút) suy ra thời gian giữ nhiệt của nồi tiệt trùng là 14 phút ở nhiệt độ xử lý $121^{0} \mathrm{C}$.

Từ đồ thị semilog Hình 2 thông qua phương trình đường thẳng $\mathrm{y}=78,088^{\mathrm{e}-0,059 \mathrm{x}}$ tính được giá trị $\mathrm{f}_{\mathrm{h}}=39,03$ phút và yếu tố trễ pha $\mathrm{j}_{\mathrm{h}}=$ 1,26 . Kết quả thẩm tra cho thấy, Fthực tế $=3,45$ $>\mathrm{F}_{0}=2,8$, cho nên có thể kết luận rằng chế độ tiệt trùng tại $121 \mathrm{oC}$ với thời gian giữ nhiệt của nồi tiệt trùng là 14 phút đã đạt giá trị tiệt trùng Fo. Kết quả của lần lặp 2 cho kết quả $\mathrm{F}_{\text {thực tế }}=$ $3,49>\mathrm{F}_{0}=2,8$ cũng đạt giá trị tiệt trùng $\mathrm{F}_{0}$.

\subsubsection{Chế độ tiệt trùng tại nhiệt độ $116^{0} \mathrm{C}$}

Đường cong truyền nhiệt tại nhiệt độ nồi $116^{0} \mathrm{C}$ thể hiện trong Hình 3.

Từ đồ thị semilog Hình 3 thông qua phương trình đường thẳng $\mathrm{y}=65,464 \mathrm{e}^{-0,06 \mathrm{x}}$ tính được giá trị $\mathrm{f}_{\mathrm{h}}=38,38$ phút và sự chênh lệch giữa đường cong truyền nhiệt và đường thẳng biểu kiến tính được $\mathrm{j}_{\mathrm{h}}=1,13$. Sau 38,38 phút thì đường thẳng đi qua 1 chu kì log, sự khác nhau giữa phần bị chắn

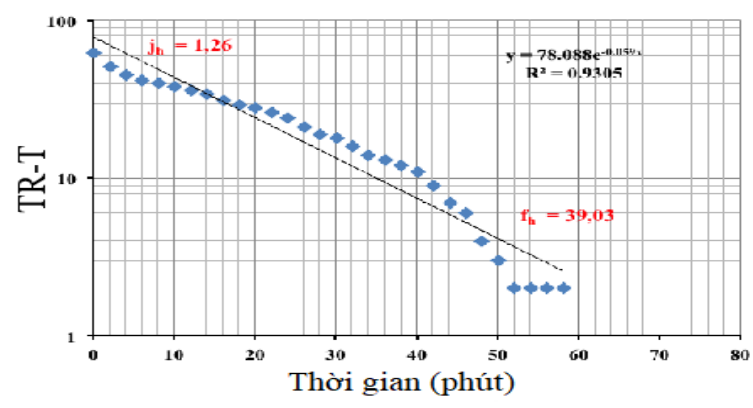

Hình 2. Đường cong truyền nhiệt của sản phẩm khi thẩm tra tại nhiệt độ nồi $121^{\circ} \mathrm{C}$.

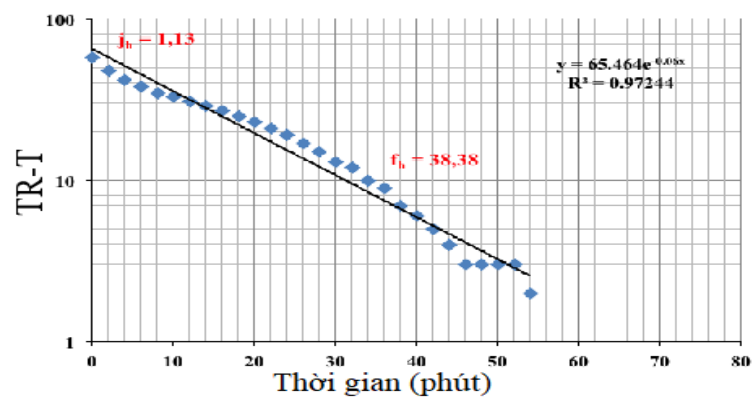

Hình 3. Đường cong truyền nhiệt của sản phẩm ở nhiệt độ nồi $116^{0} \mathrm{C}$.

thực tế và phần bị chắn biểu kiến là 1,13 (yếu tố trễ pha). Kết quả tính toán cho thấy thời gian xử lý nhiệt Ball là 43,59 phút tại $116^{\circ} \mathrm{C}$. Nhưng trong thực tế có thể thiết bị hoạt động không ồn định, nhiệt bị thất thoát nên cần bù khoảng hao hụt đó, tức là thời gian xử lý nhiệt Ball thực tế cần 45,77 phút (bù thêm $5 \%$ ).

Từ công thức Ball: $\mathrm{t}_{\mathrm{B}}=0,42 \mathrm{t}_{\mathrm{c}}+\mathrm{t}_{\mathrm{p}}$ (với $\mathrm{t}_{\mathrm{c}}=$ 44 phút) suy ra thời gian giữ nhiệt của nồi tiệt trùng là 27 phút ở nhiệt độ xử lý $116^{0} \mathrm{C}$.

Thẩm tra lại chế độ tiệt trùng vừa chọn bằng cách tính $\mathrm{F}_{\text {thực tế }}$ và so sánh với $\mathrm{F}_{0}$. Nếu Fthực tế $\geq \mathrm{F}_{0}$ thì chế độ tiệt trùng $116^{\circ} \mathrm{C}$ trong 27 phút đạt giá trị tiệt trùng $\mathrm{F}_{0}$. Tiến hành thẩm tra giá trị tiệt trùng của chế dộ tiệt trùng $116^{0} \mathrm{C}$ trong 27 phút thu được kết quả như trong Hình 4.

Từ đồ thị semilog Hình 4 thông qua phương 


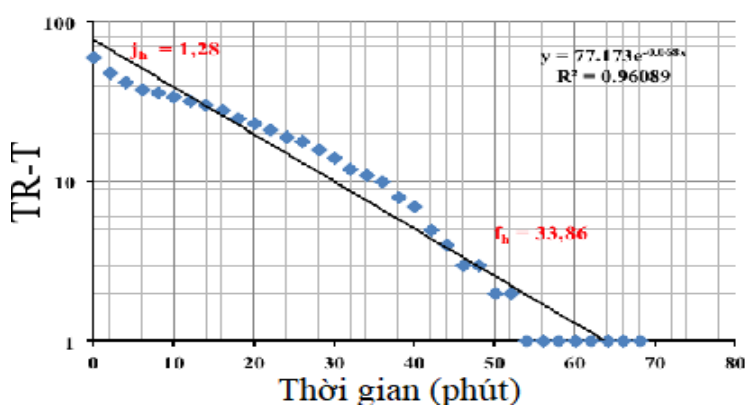

Hình 4. Đường cong truyền nhiệt của sản phẩm khi thẩm tra tại nhiệt độ nồi $116^{0} \mathrm{C}$.

trình đường thẳng $\mathrm{y}=77,173 \mathrm{e}^{-0,068 \mathrm{x}}$ tính được giá trị $\mathrm{f}_{\mathrm{h}}=33,86$ phút và yếu tố trễ pha $\mathrm{jh}=1,28$. Kết quả thẩm tra cho thấy, $\mathrm{F}_{\text {thực tế }}=3,41>\mathrm{F}_{0}$ $=2,8$, cho nên có thể kết luận rằng chế độ tiệt trùng tại $116^{0} \mathrm{C}$ với thời gian giữ nhiệt của nồi tiệt trùng là 27 phút đã đạt giá trị tiệt trùng $\mathrm{F}_{0}$. Kết quả của lần lặp 2 cho ra $\mathrm{F}_{\text {thức tế }}=3,22$ phút $>\mathrm{F}_{0}=2,8$ cũng đạt giá trị tiệt trùng $\mathrm{F}_{0}$.

Chế độ tiệt trùng $121^{\circ} \mathrm{C}$ trong 14 phút và $116^{0} \mathrm{C}$ trong 27 phút là 2 chế độ tiệt trùng đạt giá trị tiệt trùng $\mathrm{F}_{0}$. Để đảm bảo chất lượng vi sinh của cả hai chế độ xử lý, các mẫu được tiến hành kiểm tra các chỉ tiêu vi sinh và kết quả được thể hiện trong Bảng 2. Kết quả kiểm tra vi sinh cho thấy sau quá trình tiệt trùng ở 2 chế độ $116^{0} \mathrm{C}$ trong 27 phút và $121^{0} \mathrm{C}$ trong 14 phút không phát hiện vi khuẩn hiếu khí và vi khuẩn kỵ khí khử sulfite. Điều này chứng tỏ cả hai chế độ tiệt trùng đảm bảo chất lượng vi sinh.

\section{2. Ảnh hưởng của chế độ tiệt trùng đến pH và màu sắc}

Chỉ số pH: Bảng 3 thể hiện chỉ số pH ở 2 chế dộ tiệt trùng $116^{0} \mathrm{C}$ trong 27 phút và $121^{\circ} \mathrm{C}$ trong 14 phút. Kết quả cho thấy, chỉ số $\mathrm{pH}$ ở 2 chế độ tiệt trùng $116^{\circ} \mathrm{C}$ trong 27 phút và $121^{\circ} \mathrm{C}$ trong 14 phút khác biệt không ý nghĩa về mặt thống kê $(P>0,05)$. Như vậy, nhiệt độ và thời gian tiệt trùng ở 2 chế độ tiệt trùng này không ảnh hưởng đến chỉ số pH.

Tương tự, kết quả đo màu nhận thấy không có sự khác biệt đáng kể về mặt thống kê giữa 2 chế độ tiệt trùng $116^{0} \mathrm{C}$ trong 27 phút và $121^{\circ} \mathrm{C}$ trong 14 phút $(P>0,05)$. Do vậy, 2 chế độ tiệt trùng $116^{0} \mathrm{C}$ trong 27 phút và $121^{\circ} \mathrm{C}$ trong 14 phút không ảnh hưởng tới giá trị màu sắc của sản phẩm.

\section{3. Ảnh hưởng của chế độ tiệt trùng đến cảm quan}

Điểm cảm quan của sản phẩm tiệt trùng ở 2 chế độ $116^{\circ} \mathrm{C}$ trong 27 phút và $121^{\circ} \mathrm{C}$ trong 14 phút được trình bày qua Bảng 4 . Kết quả xử lý số liệu thống kê cho thấy, chế độ tiệt trùng có ảnh hưởng đến mùi và điểm trung bình tổng của sản phẩm $(P<0,05)$. Tuy nhiên, không có sự khác biệt đáng kể về vị, màu sắc và trạng thái khác khi sản phẩm xử lý ở 2 chế độ tiệt trùng khác nhau $(P>0,05)$.

Kết quả khảo sát từ các cảm quan viên cho thấy mùi của sản phẩm nước cốt xương cá hồi là chỉ tiêu có hệ số trọng lượng cao $(1,4)$, do đó mùi đóng vai trò quan trọng và đóng góp vào điểm tổng có trọng lượng của sản phẩm. Cũng theo nhận xét của cảm quan viên, chế độ $116^{0} \mathrm{C}$ trong 27 phút có mùi nấu nhiều hơn khiến họ không ưa thích bằng chế độ $121^{0} \mathrm{C}$ trong 14 phút. Tiệt trùng ở nhiệt độ cao trong thời gian ngắn giữ được giá trị cảm quan về mùi cao hơn chế độ tiệt trùng ở nhiệt độ thấp trong thời gian dài.

\subsection{Kiểm tra và đánh giá chất lượng vi sinh của sản phẩm nước cốt xương cá hồi}

Kết quả kiểm tra vi sinh vật trong sản phẩm nước cốt xương cá hồi (được xử lý tiệt trùng ở nhiệt độ $121^{0} \mathrm{C}$ trong 14 phút) sau 21 ngày bảo ôn theo Quyết định Bộ Y Tế, số 46/2007/QĐBYT. Kết quả kiểm tra vi sinh được trình bày ở Bảng 5. Kết quả kiểm tra vi sinh cho thấy, nước cốt xương cá hồi đạt tiêu chuẩn an toàn về mặt vi sinh, thoả mãn yêu cầu của Bộ Y Tế theo quyết định số 46/2007/QĐ-BYT.

\subsection{Xác định thời gian bảo quản sản phẩm nước cốt xương cá hồi}

Thời gian bảo quản sản phẩm được dự đoán theo chỉ tiêu màu sắc và cảm quan của sản phẩm từ các số liệu động học thu thập khi bảo quản ở các nhiệt độ và thời gian khác nhau. Các Bảng 6 và 7 lần lượt trình bày các số liệu động học của màu sắc và cảm quản của sản phẩm.

Kết quả đo màu của sản phẩm nước cốt xương cá hồi cho thấy các giá trị màu sắc $\mathrm{L}^{*}, \mathrm{a}^{*}, \mathrm{~b}^{*}$ không có sự thay đổi đáng kể khi bảo quản ở nhiệt độ $30^{\circ} \mathrm{C}$ sau 60 ngày. Giá trị $\mathrm{L}^{*}, \mathrm{a}^{*}$, b* của sản phẩm có sự khác biệt tương đối khi bảo quản ở nhiệt độ 45 và $52^{\circ} \mathrm{C}$ sau 20 ngày. Trước khi đưa nước cốt xương cá hồi vào bảo quản thì 
Bảng 2. Kết quả vi sinh vật của sản phẩm trước khi tiệt trùng

\begin{tabular}{llcl}
\hline Chế độ tiệt trùng & Chỉ tiêu & Đơn vị tính & Kết quả \\
\hline \multirow{2}{*}{$116^{0} \mathrm{C}$ và 27 phút } & Tổng số vi sinh vật hiếu khí & CFU/mL & Không phát hiện \\
& Tổng số vi sinh vật ky khí khử sulfite & CFU/mL & Không phát hiện \\
\multirow{2}{*}{$121^{0} \mathrm{C}$ và 14 phút } & Tổng số vi sinh vật hiếu khí & CFU $/ \mathrm{mL}$ & Không phát hiện \\
& Tồng số vi sinh vật kỵ khí khử sulfite & $\mathrm{CFU} / \mathrm{mL}$ & Không phát hiện \\
\hline
\end{tabular}

Bảng 3. Ảnh hưởng của chế độ tiệt trùng đến $\mathrm{pH}$ và màu sắc của sản phẩm

\begin{tabular}{lcccc}
\hline Chế độ & $\mathrm{pH}$ & $\mathrm{L}$ & $\mathrm{a}^{*}$ & $\mathrm{~b}^{*}$ \\
\hline $116^{0} \mathrm{C} / 27$ phút & $5,58 \pm 0,01^{\mathrm{a}}$ & $64,8 \pm 0,2^{\mathrm{a}}$ & $1,7 \pm 0,0^{\mathrm{a}}$ & $17,2 \pm 0,3^{\mathrm{a}}$ \\
$121^{0} \mathrm{C} / 14$ phút & $5,59 \pm 0,00^{\mathrm{a}}$ & $65,0 \pm 0,7^{\mathrm{a}}$ & $1,7 \pm 0,0^{\mathrm{a}}$ & $17,3 \pm 0,4^{\mathrm{a}}$ \\
\hline
\end{tabular}

Bảng 4. Điểm cảm quan (điểm có trọng lượng) của sản phẩm tiệt trùng hai chế độ khác nhau

\begin{tabular}{lccccc}
\hline Chế độ tiệt trùng & Mùi & Vị & Màu sắc & Trạng thái & $\begin{array}{c}\text { Tổng điểm } \\
\text { cảm quan }\end{array}$ \\
\hline $116^{0} \mathrm{C} / 27$ phút & $4,96 \mathrm{a} \pm 0,20$ & $4,73^{\mathrm{a}} \pm 0,30$ & $1,77^{\mathrm{a}} \pm 0,16$ & $2,48^{\mathrm{a}} \pm 0,05$ & $13,93^{\mathrm{a}} \pm 0,29$ \\
$121^{0} \mathrm{C} / 14$ phút & $5,78^{\mathrm{b}} \pm 0,35$ & $5,08^{\mathrm{a}} \pm 0,46$ & $1,90^{\mathrm{a}} \pm 0,14$ & $2,65^{\mathrm{a}} \pm 0,09$ & $15,40^{\mathrm{b}} \pm 0,34$ \\
\hline
\end{tabular}

${ }^{\mathrm{a}-\mathrm{b}}$ Các ký tự khác nhau trên cùng một cột thể hiện sự khác biệt có ý nghĩa về mặt thống kê giữa các nghiệm thức ở độ tin cậy $95 \%$.

Bảng 5. Kết quả kiểm tra vi sinh vật trong sản phẩm nước cốt xương cá hồi

\begin{tabular}{llccc}
\hline STT & Chỉ tiêu & Giới hạn vi sinh vật & Đơn vị & Kết quả \\
\hline 1 & Tổng số vi sinh vật hiếu khí (TPC) & - & $\mathrm{CFU} / \mathrm{mL}$ & $<1$ \\
2 & Vi khuẩn kỵ khí sinh $\mathrm{H}_{2} \mathrm{~S}$ & - & $\mathrm{CFU} / \mathrm{mL}$ & $<1$ \\
3 & Clostridium botulinum & Không có & $\mathrm{CFU} / \mathrm{mL}$ & Không phát hiện \\
4 & Clostridium perfringens & Không có & $\mathrm{CFU} / \mathrm{mL}$ & $<1$ \\
5 & Escherichia coli & Không có & $\mathrm{CFU} / \mathrm{mL}$ & $<1$ \\
6 & Staphylococcus aureus & Không có & $\mathrm{CFU} / \mathrm{mL}$ & $<1$ \\
\hline
\end{tabular}

"-" không quy định.

Bảng 6. Sự suy giảm động học về chỉ tiêu màu sắc của nước cốt xương cá hồi

\begin{tabular}{llccc}
\hline Nhiệt độ $\left({ }^{0} \mathrm{C}\right)$ & Tốc độ suy thoái k $(1 /$ ngày $)$ & Half life & $\mathrm{R}^{2}$ & Phương trình \\
\hline 30 & 0,0076 & 91,2036 & 0,7619 & $\mathrm{y}=0,0076 \mathrm{x}-0,0152$ \\
45 & 0,0444 & 15,6114 & 0,927 & $\mathrm{y}=0,0444 \mathrm{x}+0,9736$ \\
52 & 0,0468 & 14,8108 & 0,9468 & $\mathrm{y}=0,0468 \mathrm{x}+1,1652$ \\
\hline
\end{tabular}

Bảng 7. Sự suy giảm động học về điểm cảm quan của nước cốt xương cá hồi

\begin{tabular}{llccc}
\hline Nhiệt độ $\left({ }^{0} \mathrm{C}\right)$ & Tốc độ suy thoái $\mathrm{k}(1 /$ ngày $)$ & Half life & $\mathrm{R}^{2}$ & Phương trình \\
\hline 30 & 0,0059 & 117,4826 & 0,9322 & $\mathrm{y}=-0,0059 \mathrm{x}-0,0074$ \\
45 & 0,0279 & 24,8440 & 0,9780 & $\mathrm{y}=-0,0279 \mathrm{x}+0,0214$ \\
52 & 0,0361 & 19,2008 & 0,9877 & $\mathrm{y}=-0,0361 \mathrm{x}+0,0029$ \\
\hline
\end{tabular}

sản phẩm có màu sắc sáng hơn, vàng tươi hơn; khi tiến hành bảo quản, màu sắc của nước cốt xương cá hồi có xu hướng tối màu dần. Cụ thể, ở nhiệt độ 45 và ở $52^{0} \mathrm{C}$ trong 20 ngày, giá trị $\mathrm{L}^{*}$ giảm lần lượt khoảng 3 và 4 đơn vị; đồng thời $\mathrm{a}^{*}$ tăng lần lượt 0,5 và 0,6 đơn vị; $b^{*}$ lần lượt không thay đổi nhiều và dao động hơn 1 đơn vị. Tương tự như vậy, các nghiên cứu khác cũng đã báo cáo màu sắc của các mẫu có chứa carotenoid đã bị ảnh hưởng đáng kể bởi nhiệt độ lưu trữ cao và thời gian dài (Chen \& Tang, 1998; Duangmal \& ctv., 2008).

Sự khác biệt màu sắc $(\Delta \mathrm{E})$ từ 0 đến 1,5 được xem là nhỏ và hầu như giống hệt nhau nếu quan 
sát bằng mắt thường, $\Delta \mathrm{E}$ nằm trong khoảng từ 1,5 đến 5 thì khác biệt màu sắc có thể được biểu lộ, trong khi $\Delta \mathrm{E}$ lớn hơn 5 thì biểu hiện một cách rõ ràng (Obón \& ctv., 2009). Vì thế chọn $\Delta \mathrm{E}=$ 5 là giá trị tới hạn mà ở đó thời gian bảo quản sản phẩm kết thúc.

Bảng 6 thể hiện sự thay đổi động học về chỉ tiêu màu sắc $(\Delta \mathrm{E})$ giữa các mẫu nước cốt xương cá hồi trước và sau khi bảo quản ở nhiệt độ trong các khoảng thời gian khác nhau. Kết quả cho thấy sự gia tăng tổng khác biệt màu sắc trong các mẫu bảo quản phù hợp với phản ứng bậc một, nhiệt độ càng cao thì thời gian bảo quản càng ngắn, sự khác biệt màu sắc càng lớn so với ban đầu. Từ đó, cho thấy tỷ lệ suy thoái màu sắc càng tăng và thời gian bảo quản càng giảm khi nhiệt độ bảo quản tăng dần. Tốc độ suy thoái màu sắc tăng cao khi nhiệt độ bảo quản càng cao, cụ thể khi bảo quản ở $45^{\circ} \mathrm{C}$ và $52^{\circ} \mathrm{C}$, thì tốc độ suy thoái tăng gấp 5,8 lần và gấp 6,2 lần so với nhiệt độ $30^{\circ} \mathrm{C}$.

Theo kết quả Bảng 6, sự gia tăng tổng khác biệt màu sắc trong các mẫu bảo quản phù hợp với phản ứng bậc một, nhiệt độ càng cao thì thời gian bảo quản càng ngắn, sự khác biệt màu sắc càng lớn so với ban đầu. Từ đó, cho thấy tỷ lệ suy thoái màu sắc càng tăng và thời gian bảo quản càng giảm, là kết quả khi bảo quản ở các nhiệt độ tăng dần. Tốc độ suy thoái màu sắc tăng cao khi nhiệt độ bảo quản càng cao, cụ thể khi bảo quản ở 45 và $52^{0} \mathrm{C}$, thì tốc độ suy thoái tương ứng tăng gấp 5,8 lần và gấp 6,2 lần so với nhiệt độ $30^{\circ} \mathrm{C}$.

Bảo quản sản phẩm nước cốt xương cá hồi ở nhiệt độ cao trong thời gian dài làm giảm điểm cảm quan sản phẩm; cụ thể sau 30 ngày bảo quản ở nhiệt độ 45 và 23 ngày ở $52^{\circ} \mathrm{C}$ thì tổng điểm cảm quan có trọng lượng đã vào mức kém, tổng điểm có trọng lượng của nước cốt xương cá hồi ở hai điều kiện này được dự đoán đạt loại rất kém (điểm chung từ 4 đến 7,1) theo TCVN 3215 - 79, cho thấy mức độ không chấp nhận của cảm quan viên về sản phẩm càng tăng cao khi bảo quản ở nhiệt độ cao trong thời gian dài. Tổng điểm có trọng lượng của nước cốt xương cá hồi nên từ 7,2 điểm trở lên - còn khả năng bán được, là điểm tới hạn mà ở đó thời gian bảo quản sản phẩm kết thúc.

Kết quả đã xác định được phương trình suy giảm bậc một cho thông số cảm quan của nước cốt xương cá hồi tại 3 nhiệt độ bảo quản theo thời gian và dự đoán được thời gian hư hỏng tại 3 nhiệt độ bảo quản. Bảng 7 cho thấy sự giảm điểm cảm quan trong các mẫu phù hợp với phương trình bậc nhất, nhiệt độ càng cao thì thời gian bảo quản càng ngắn, tổng điểm có trọng lượng giảm. Nhìn chung, tốc độ suy thoái càng tăng lên và thời gian bảo quản giảm do tổng điểm cảm quan có trọng lượng giảm, đó là kết quả khi tăng nhiệt độ bảo quản từ 30 lên $52^{0} \mathrm{C}$. Cụ thể, tỷ lệ suy thoái $(\mathrm{k}=0,0059 /$ ngày) của nước cốt xương cá hồi bảo quản ở $30^{\circ} \mathrm{C}$ thấp hơn nhiều so với mẫu bảo quản ở nhiệt độ cao, nhỏ hơn khoảng 5 lần khi bảo quản ở nhiệt độ $45^{\circ} \mathrm{C}$ và 6 lần ở nhiệt độ $52^{0} \mathrm{C}$

Sự gia tăng khác biệt về màu sắc và cảm quan của sản phẩm nước cốt xương cá hồi tại các nhiệt độ khác nhau được thể hiện đầy đủ như một phương trình bậc một khi sản phẩm được bảo quản trong vùng nhiệt độ 30 đến $52^{0} \mathrm{C}$, cho phép ước lượng tốc độ suy thoái $\mathrm{k}$ ở nhiệt độ tham chiếu $\left(30^{\circ} \mathrm{C}\right)$ bằng phương trình hồi quy tuyến tính (Hình 5). Sự phụ thuộc vào nhiệt độ của sự thay đổi màu sắc được vẽ trong đồ thị Arrhenius. Từ đó, năng lượng hoạt hóa hay năng lượng cần thiết cho sự phá hủy màu sắc là $17,29 \mathrm{kcal} / \mathrm{mol}$. Tương tự, năng lượng hoạt hóa cho sự suy giảm điểm cảm quan là 16,77 kcal/mol.

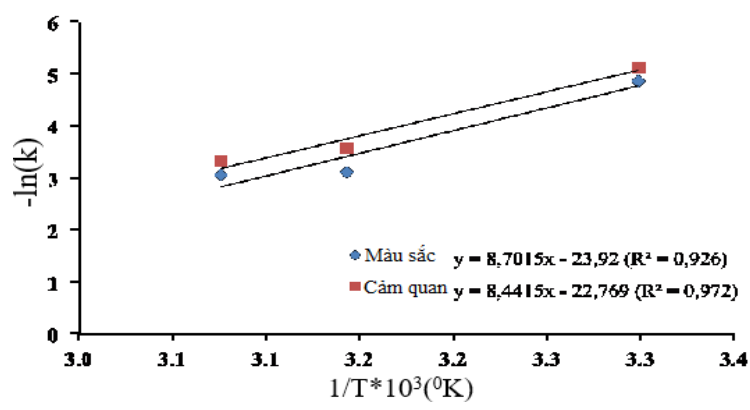

Hình 5. Đồ thị Arrhenius xác định thất thoát màu sắc và cảm quan của sản phẩm.

\section{Kết Luận}

Nghiên cứu đã xác định được chế độ tiệt trùng thích hợp cho sản phẩm nước cốt xương cá hồi đóng lon là $121^{\circ} \mathrm{C}$ trong 14 phút. Ở chế độ tiệt trùng này, sản phẩm đảm bảo an toàn về mặt vi sinh, màu sắc và chất lượng cảm quan. Nghiên cứu cũng đã xác định được thời gian bảo quản sản phẩm nước cốt xương cá hồi là 19 tháng trong điều kiện lon sản phẩm đảm bảo độ kín, không gỉ sét, không bị biến dạng trong suốt thời gian bảo quản. 


\section{Tài Liệu Tham Khảo (References)}

Chen, B. H., \& Tang, Y. C. (1998). Processing and stability of carotenoid powder from carrot pulp waste. Journal of Agricultural and Food Chemistry 46(6), 23122318 .

Duangmal, K., Saicheua, B., \& Sueeprasan, S. (2008). Colour evaluation of freeze-dried roselle extract as a natural food colorant in a model system of a drink. LWT-Food Science and Technology 41(8), 1437-1445.

Fellows, P. J. (2009). Food processing technology: Principles and practice ( $2^{\text {nd }}$ ed.). Cambridge, UK: Woodhead.

Fu, B., \& Labuza, T. P. (1993). Shelf-life prediction: Theory and application. Food Control 4(3), 125-133.

Ha, T. D. (2000). Food Sensory Evaluation Techniques. Ha Noi, Viet Nam: Science and Technics Publishing House.
Obón, J. M., Castellar, M. R., Alacid, M., \& FernándezLópez, J. A. (2009). Production of a red-purple food colorant from Opuntia stricta fruits by spray drying and its application in food model systems. Journal of Food Engineering 90(4), 471-479.

Pflug, I. J., Berry M. R., \& Dignan, D. M. (1990). Establishing the heat-preservation process for asepticallypackaged low-acid food containing large particulates, sterilized in a continuous heat-hold-cool system. Journal of Food Protection 53(4), 312-320.

Stoforos, N. G. (2010). Thermal process calculations through ball's original formula method: A critical presentation of the method and simplification of its use through regression equations. Food Engineering Reviews 2(1), 1-16. 